\title{
FILOSOFIA NA ESCOLA:
}

\section{Uma apresentação}

\author{
Álvaro Sebastião Teixeira Ribeiro (1) \\ Dante Diniz Bessa (2)
}

Resumo: Nosso objetivo com o texto é o de apresentar o projeto Filosofia na Escola aos leitores, visando uma melhor compreensão dos demais textos que constituem o "Dossiê Filosofia na Escola". Nessa apresentação destacamos, primeiro, aspectos históricos e estatísticos; em seguida, alguns princípios norteadores da produção teórica e prática, bem como momentos e atividades da organização do projeto e, por fim, procuramos indicar os sinais que orientaram as investigações no ano de 2004 e que resultaram nos textos constituintes do Dossiê.

No texto que segue não pretendemos estabelecer nenhuma problematização específica a ser pensada e discutida. É possível, entretanto, que algumas questões venham a se colocar para os leitores, as quais não nos incomodaríamos em compartilhar numa investigação. Insistimos, entretanto, que o objetivo com o texto não é outro senão o de oferecer algumas informações gerais sobre o projeto Filosofia na Escola, com vistas a contextualizar a leitura dos demais textos que constituem esse dossiê sobre o projeto, nos quais, aí sim, algumas questões se colocam para a investigação, reflexão e discussão.

Com esse objetivo, então, o texto está organizado em três partes. Na primeira apresentamos um rápido histórico com alguns dados estatísticos sobre o projeto. Na segunda apresentamos o modo como o projeto esteve "organizado" no ano de 2004 e, por último, fazemos algumas considerações a respeito do foco de investigação do projeto nesse mesmo ano, tentando, ao mesmo tempo, indicar alguma situação nova que o projeto possa estar possibilitando sobre essa temática de investigação.

\section{Informações históricas e estatísticas}

O projeto Filosofia na Escola é uma atividade contínua de extensão da Faculdade de Educação da Universidade de Brasília (UnB), envolvendo professores e alunos da UnB e professores e alunos de escolas públicas do Distrito Federal, numa aposta de que nem idades e nem lugares são empecilhos para o filosofar.

Em 1996, Ann Margaret Sharp, uma das colaboradoras de Matthew Lipman (o filósofo criador do Programa de Filosofia para Crianças), professora do IAPC (Institute for the Advancement of Philosophy for Children), Montclair State University, e Walter O. Kohan, professor do Departamento de Filosofia da Universidade de Buenos Aires, ofereceram um curso na Universidade de Brasilia 
que contou com a participação de mais de 100 estudantes universitários e professores de escolas públicas e privadas.

Em junho de 1997, Walter Kohan, já professor da Faculdade de Educação da UnB, e Ana Míriam Wüensch, do Departamento de Filosofia, realizaram oficinas, palestras e projeções de vídeos sobre o filosofar com crianças para mais de 200 pessoas. Em julho daquele ano, mais de 120 pessoas participaram de uma jornada sobre a filosofia na educação das crianças que contou mais uma vez com a presença de Ann Sharp. Outros pequenos cursos foram realizados. Gradativamente criava-se um contexto na universidade e em diversas escolas para a acolhida de uma experiência piloto: o Projeto Filosofia na Escola.

O Projeto Filosofia na Escola foi aprovado em dezembro de 1997 como um projeto de extensão da UnB. Sua proposta era (e continua sendo) a de possibilitar o encontro entre professores universitários, estudantes de cursos como filosofia, pedagogia, psicologia (os quais chamamos mediadores), professores e alunos de escolas públicas pelo exercício da filosofia.

Em fevereiro de 1998 ocorreu o primeiro curso de formação do Projeto Filosofia na Escola. O curso seria uma etapa inicial para o trabalho que duraria o ano inteiro nas escolas. Para este curso, candidataram-se mais de 30 escolas e cerca de 140 professores. Foram selecionadas 4 escolas públicas de localizações geográficas bastante distintas, características sócio-econômicas diferenciadas, que reuniam um número razoável de professores interessados e que se propuseram a disponibilizar tempo para as atividades do projeto. Trinta pessoas participaram do primeiro curso de formação oferecido pelo projeto. $O$ trabalho transcorreu nas escolas e na universidade durante todo o ano de 1998.

Inicialmente previsto para durar 2 (dois) anos, o projeto encontra-se frente à demanda para sua continuidade e ampliação, pois o trabalho desenvolvido ao longo destes anos com os (as) professores (as) regentes de classe (na Educação Infantil e Ensino Fundamental), demonstraram a possibilidade concreta destes profissionais engajarem-se em investigações filosóficas coletivas. O Projeto tem gerado uma atitude reflexiva nos professores, em que a discussão transdisciplinar surge de forma enfática. A prática da sala de aula e a postura requisitada na prática de filosofia têm orientado a expansão dos princípios exigidos na ação filosófica.

O projeto Filosofia na Escola, em suas atividades de extensão universitária, já envolveu, ao longo dos seus oito anos de ação, 21 professores universitários, 150 estudantes de graduação, 710 professores da escola básica e alfabetizadores e mais de oito mil estudantes da educação infantil, do ensino fundamental e do ensino médio. Além disso, o projeto tem possibilitado uma ampla produção teórica, entre livros, dissertações de mestrado, artigos, comunicações em eventos científicos e trabalhos de final de curso, abordando os diversos aspectos implicados nas suas atividades.

\section{Organização do projeto Filosofia na Escola}




\subsection{Pressupostos}

O projeto Filosofia na Escola tem como primeiropressuposto o de que os conhecimentos teóricos e práticos exigidos nas suas ações são produzidos num processo de reflexão, problematização e investigação na e sobre a vivência, de modo a que se possa viver e pensar a filosofia junto com as crianças, criando $e$ discutindo as condições de possibilidade para isso.

Há que se compreender, com isso, que o projeto está aberto. Estar aberto significa que não se tem nenhum modelo já elaborado visando a eficácia e a eficiência do pensar filosófico nas escolas. Interessa que os sujeitos do projeto se coloquem na condição de refletir, problematizar e investigar essas condições com base na sua vivência, sabendo que o projeto envolve conhecimentos, reflexões e investigações relativos ao pensar filosófico, ao pensar das crianças e jovens, ao pensar com crianças e jovens, ao sentido da presença da filosofia nas escolas, ao sentido da educação escolar, entre outros conhecimentos.

O que se pretende com o projeto, então, refere-se à criação de um espaço de autonomia; que o Projeto Filosofia na Escola seja um espaço de autonomia. Há nisso um segundo pressuposto, como propõe Nascimento (2003), interpretando Foucault:

"que os espaços onde os acontecimentos se realizam são construídos, que o próprio espaço tem uma história, não é uma condição da qual não temos escapatória; (...) que esses espaços podem ser criados para fazer com que eventos improváveis possam acontecer. Não criar o evento, mas criar o espaço para ele, isto é, abrir o espaço para que a utopia possa se realizar. A esses espaços onde as utopias são efetivamente realizáveis, Foucault chama de heterotopias (hétérotopies) isto é, espaços outros, espaços diferentes dos que já se tem como dados. (...) Esses são espaços sem formas predefinidas, que não podem ser universalizados, são lugares que se deslocam, que não são fixos e nem rígidos, mas que respondem a uma necessidade de fazer trazer ao mundo a diferença, que em nosso caso aparece como a utopia" (p 10).

Por fim, um terceiro pressuposto está colocado, relativamente aos anteriores: o de que os espaços da autonomia e as vivências do projeto sejam coletivos. Quer dizer que entendemos os espaços e as vivências como múltiplos espaços e múltiplas vivências que, ao se encontrarem uns com os outros, constituam o projeto como fluxo, como deslocamentos de aprendizagem, de ensino e de criação.

\subsection{Relação entre ensino, pesquisa e extensão}

Embora o projeto Filosofia na Escola seja formalmente um projeto de extensão universitária, suas ações têm dado claros sinais de que extensão, pesquisa e ensino não são atividades dissociadas e que, portanto, não precisamos separá-las, classificá-las e estabelecer quaisquer relações de hierarquia entre elas e entre os sujeitos envolvidos com elas, do tipo: primeiro os pesquisadores produzem conhecimentos (pesquisa), depois os professores os transmitem aos estudantes 
(ensino), para que, por último, esses conhecimentos sejam aplicados em outros sujeitos e espaços (extensão).

No projeto, os diferentes sujeitos têm podido estar em movimento permanente de investigação e reflexão sobre o que vivenciam, isto é, todos têm podido ser pesquisadores, professores e extensionistas, pois que todos são aprendentes de si, de saberes, de práticas.

As práticas do projeto são práticas coletivas que dão conta de criar condições para o encontro de diferentes sujeitos, diferentes saberes e diferentes fazeres. Enfim, as práticas coletivas do projeto acolhem uma pluralidade de possibilidades que potencializa experiências individuais de modo a que pode se tornar possível a desdisciplinarização dos sujeitos e dos sabares, de um lado e, de outro lado, pode potencializar o aprofundamento de saberes disciplinares, conforme a opção que se venha a fazer.

\subsection{As atividades do projeto}

No que toca às atividades do projeto, podemos distinguir três práticas formais: 1) as oficinas com crianças nas escolas, que estaria envolvendo diretamente a comunidade escolar (alunos e professores) e os mediadores; 2) os grupos de estudos, momento da prática de pesquisa e reflexão cujo ponto de partida são os problemas (teórico-práticos / filosófico-pedagógicos) enfrentados nas práticas escolares e colocados através de relatos de experiência, que envolvem diretamente mediadores, professores e coordenadores e 3) os encontros gerais mensais, momento da prática de trocas de experiência, de avaliação e problematização das práticas, além de apresentação do que se tem produzido nos grupos de estudos, que realimentam o projeto teoricamente, envolvendo todos os sujeitos, exceto os alunos das escolas.

Essas três atividades se distinguem e se encontram, também, quanto aos seus objetivos. As oficinas com as crianças são a razão de ser do projeto, é para isso que ele existe, já que o objetivo principal é o de criar condições para que as crianças possam experimentar o pensar e tornar o pensamento vivo, podendo estabelecer outras relações com o saber, com outras pessoas e consigo mesmas. É o que define a política do projeto e exige dele uma postura política. Os encontros gerais, por sua vez, são momentos de reflexão conjunta dos coordenadores, professores $e$ mediadores, cujos objetivos são os de relatar as práticas de extensão, avaliá-las e problematizá-las em relação às possibilidades da experiência das crianças com o pensar. Os grupos de estudos, por fim, têm os objetivos de investigar, de discutir e de criar, a partir da experiência e de produções teóricas já elaboradas, outras condições para a experiência das crianças com o pensar, conforme os problemas sejam colocados nas práticas escolares.

\subsection{Os sujeitos do projeto}

Os alunos da educação infantil, do ensino fundamental e médio de escolas públicas do Distrito Federal, que participam do projeto através das oficinas realizadas nas 
escolas, semanalmente, e de outras atividades eventuais pelas quais se procura possibilitar encontros entres as escolas.

Os professores das escolas, que participam como cursistas de extensão (formação continuada) e como coordenadores das atividades com os alunos, pensando, investigando e criando as condições de possibilidade para o acontecer do projeto.

Os mediadores são estudantes universitários, profissionais em formação inicial, que participam do projeto através de espaços curriculares dos cursos que freqüentam ou como bolsistas de extensão. São mediadores no sentido de que fortalecem a relação universidade escola e fazem transitar os conhecimentos e problemas de um lugar para o outro. Para isso, os mediadores participam de todas as atividades junto com os professores das escolas.

\section{0 foco de investigação no projeto em 2004}

Embora o objetivo central do projeto venha sendo criar as condições para a experiência do pensar de crianças e jovens, a investigação proposta em 2004 estabeleceu como problemática central a relação do professor (formação continuada ou inicial) com a filosofia, como elemento constituinte da sua formação e atuação, e de como a experiência com ela (a filosofia) na escola pode ganhar sentido no que diz respeito à organização do trabalho pedagógico .

A atenção à formação de professores e à organização do trabalho pedagógico na escola sempre esteve presente no projeto Filosofia na Escola, senão por outros motivos, pelo menos porque, na busca de criar condições para a experiência de crianças e jovens com a filosofia, também os professores passam a vivenciar essa experiência. Agora, efeitos e novidades que essa experiência possa estar possibilitando na atuação desses professores foram colocados para a reflexão ao longo do ano que passou e resultou nos textos que constituem o "Dossiê Filosofia na Escola"; primeiras investigações.

Essa vivência da experiência com a filosofia dos professores na escola, parece estar criando um movimento muito interessante em relação à organização do trabalho pedagógico, tanto nas reflexões como nas práticas, que parte da ocupação com as atividades de sala de aula em direção à organização e ao sentido da educação escolar, conforme indicam os textos produzidos por professores e mediadores. Em outras palavras, a ocupação dos professores em formação continuada (professores das escolas) e em formação inicial (estudantes de graduação - mediadores) com e nos encontros de filosofia com crianças parece estar criando condições para que se possa problematizar as práticas pedagógicas e os conceitos, valores e princípios que orientam essas práticas na escola, de tal sorte que a crítica, a investigação e a reflexão têm podido se tornar práticas recorrentes, postura mesmo na sua atuação docente.

Nesse sentido, o projeto Filosofia na Escola vem se constituindo e constituindo a escola como lócus da experiência com o filosofar, inserindo-se naquele espaço de formação filosófica (inicial e continuada) dos professores, porém criando uma 
situação diferente da tradicional. Uma situação de participação e experiência do professor com a investigação filosófica da educação na escola.

Como se sabe, a formação de professores tem colocado a escola como espaço educativo privilegiado que precisa ser conhecido por quem nela atua. Esse conhecimento exigido para o profissional em educação remete à investigação acerca de que ele, além de saber os conteúdos de ensino e ter conhecimentos pedagógicos precisa compreender e saber se posicionar em relação ao espaço em que vai atuar e sobre os efeitos de sua atuação nesse e em outros espaços. Nesse caso, crítica, investigação e reflexão se colocam como exigências na sua formação, tomadas como competências para o exercício profissional.

Essas exigências, para alguns, dá sentido e garante lugar à filosofia na formação do profissional em educação e na educação básica, pois seria ela a disciplina, o saber próprio para isso (Bessa, 1997).

Entretanto, se se atentar à formação filosófica dos professores, vê-se que ela tem se caracterizado, tradicionalmente, pela presença da filosofia da educação nos currículos de licenciatura (na maioria das vezes opcional), disciplina cujos conteúdos são tomados como fundantes e críticos dos saberes e das práticas pedagógicos e só muito recentemente se tem investido na postura e na investigação filosófica na educação, no Brasil, como dispositivo de formação, conforme informa Severino (2000).

Nessa tradição, a filosofia da educação tem sido produzida prioritariamente a partir da filosofia, como aplicação desta à educação, distanciando, assim, a reflexão filosófica na educação dos espaços onde esta (a educação) acontece, caracterizando-se (a filosofia da educação) ora como um refletir sobre e não na educação, ora como um fazer inferências sobre a educação a partir da filosofia, ora como um trazer à superfície a dimensão filosófica que está no fundo das práticas e teorias da educação. A função da filosofia da educação tem sido basicamente a de justificação ou de fundamentação (Hermann, 2000; Guiraldelli, 2005), crítica ou não, das teorias e práticas pedagógicas.

Quando se começa a debater o sentido e as possibilidades da investigação filosófica na educação como dispositivo de formação, contudo, o centro do debate continua sendo a disciplina filosofia da educação, espaço privilegiado na formação filosófica do profissional em educação. As questões que se colocam em torno disso dizem respeito à identidade da filosofia da educação, à sua delimitação epistemológica, suas relações com outros campos epistemológicos ou disciplinares da área da educação (didática, teoria da educação, ciências da educação) e aos saberes e competências para fazer filosofia da educação.

Neste sentido, a tendência, entre aqueles que estão envolvidos com essas questões, tem sido a posição de que a filosofia da educação exige uma abordagem técnica, como Ghiraldelli Jr. afirma (3), por exemplo, o que restringe as possibilidades da presença da filosofia na formação de profissionais da educação a produção exclusiva dos filósofos. Quer dizer, como saber especificamente filosófico, restando 
àqueles que fazem educação ter notícia, apenas, a respeito da investigação dos filósofos especializados, sem poder nem precisar eles próprios participar e ter experiência nessa produção.

Considerando isso, o projeto Filosofia na Escola tem se constituído, na prática, em espaço de interação entre investigação filosófica e pedagógica da educação na escola, promovendo e possibilitando outras relações entre filosofia e pedagogia, na medida em que situa profissionais em educação em outras relações com a filosofia e filósofos em outras relações com a pedagogia, tendo efeitos tanto sobre a filosofia da educação como sobre a organização do trabalho pedagógico, como eventualmente poderemos ver nos textos deste dossiê.

\section{REFERÊNCIAS}

BESSA, Dante Diniz. Educação Filosófica, crítica!? A filosofia como disciplina do currículo de $2^{\circ}$ grau. Porto Alegre: FACED/UFRGS, 1997. (Dissertação de Mestrado)

Tornar-se professor de filosofia: o que acontece quando filosofia $e$ pedagogia se encontram!? Comunicação apresentada no II Encontro Internacional de Filosofia e Educação. Rio de Janeiro: UERJ, 9 a 11 de setembro 2004.

GALLO, Silvio e KOHAN, Walter O. Crítica de alguns lugares-comuns ao se pensar a filosofia no Ensino Médio. In:

Petrópolis: Vozes, 2000. p. 174-196. (Orgs.) Filosofia no Ensino Médio.

GHIRALDELLI JR., Paulo (Org.). O que é Filosofia da Educação? Rio de Janeiro: DP\&A, 2000.

Filosofia da Educação. Rio de Janeiro: DP\&A, 2000. (O que você precisa saber sobre)

.Pedagogia, educação, didática e filosofia da educação - algumas distinções www.filosofia.pro.br/pedagogia.htm. Capturado em 17/02/2005.

HERMANN, Nadja. Nietzsche: uma provocação para a filosofia da educação. In: GHIRALDELLI Jr, Paulo (Org.) O que é Filosofia da Educação? Rio de Janeiro: DP\&A, 2000. p. 139-156.

KOHAN, Walter Omar; LEAL, Bernardina \& RIBEIRO, Álvaro. (Orgs.) Filosofia na Escola Pública. Petrópolis: Vozes, 2000.

NASCIMENTO, Wanderson Flor do. Notas sobre o pensar e o fazer. Um diálogo com a filosofia na formação de professores. disponível em www.unb.br/fe/revistapedagogia. 
SEVERINO, Antônio Joaquim. A Filosofia da Educação no Brasil: esboço de uma trajetória. In: Ghiraldelli Jr, Paulo (Org.). O que é Filosofia da Educação? Rio de Janeiro: DP\&A, 2000. p. 265-326.

(1) Professor da Secretaria de Educação do Distrito Federal, atuando na Universidade de Brasîia (UnB). Professor da Área Filosofia na Escola da Faculdade de Educação da UnB. E-mail: alvaro@unb.br

(2) Professor da Faculdade de Educação Universidade de Brasília, coordenador da Área Filosofia na Escola. E-mail: ddbessa@terra.com.br

(3) "O problema da pós-modernidade versus modernidade" em educação, enquanto problema técnico em filosofia da educação..."(p. 28) GHIRALDELLI JR, Paulo. Filosofia da Educação. Rio de Janeiro: DP\&A, 2000. (O que você precisa saber sobre) ou "É o trabalho próprio dos chamados filósofos da educação. Não raro, é uma discussão que envolve argumentos técnicos em filosofia e, portanto, não produz um saber que possa ser de domínio imediato dos que estão executando a relação ensino-aprendizagem..." (p. 3) GHIRALDELLI JR, Paulo. Pedagogia, educação, didática e filosofia da educação - algumas distinções.www.filosofia.pro.br/pedagogia.htm. 